\title{
PHẪU THUẬT TẠO HìnH VAN HAI LÁ ÍT XÂM LẤN CÓ NộI SOI HÕ̃ TRƠ VỚI CẢI TIẾN KĨ THUẬT BộC Lộ VAN HAI LÁ, HƯỚNG TỚI PHÃ̃U THUẬT NộI SOI TOÀN BỘ TẠI TRUNG TÂM TIM MẠCH BỆNH VIỆN E
}

\author{
Phạm Thành Đạt*, Nguyễn Công Hưư*, Lê Ngọc Thành*
}

\section{TÓM TĂT}

Nghiên cứu tiến cứu kết hợp hồi cứu mô tả 22 bệnh nhân được phẫu thuật sửa van hai lá ít xâm lấn với nội soi hỗ trợ tại Trung Tâm Tim Mạch - Bệnh Viện E từ tháng 09/2015 đến tháng 05/2017. Tất cả các bệnh nhân được phẫu thuật theo một quy trình thống nhất: siêu âm thực quản trước mổ, tuần hoàn ngoài cơ thể ngoại vi, đường mở nhỏ ngực phải $4 \mathrm{~cm}$, cặp động mạch chủ qua thành ngực, liệt tim xuôi dòng qua gốc động mạch chủ. Phương pháp bộc lộ van hai lá được cải tiến với miếng đệm tự chế và các mũi chỉ có pledgets khâu treo qua thành ngực. Van hai lá được bộc lộ hoàn chỉnh, 22 bệnh nhân thực hiện thành công phẫu thuật. Không có trường hợp nào phải mở rộng đường mở ngực hay chuyển mở xương ức. Tuổi trung bình là 45,7 $\pm 11,8$ tuổi. $22,7 \%$ nữ và $77,3 \%$ nam. Các bệnh lý phổ biến nhất là bệnh thoái hoá van hai lá type II (77,3\%), dựa trên phân loại Carpentier, bệnh van hai lá do thấp type I (18,2\%). Thời gian chạy máy TNHCT 208.95 \pm 43.68 phút, thời gian cặp động mạch chủ $143.09 \pm 39.95$ phút. Kỹ thuật tạo hình van hai lá bao gồm: đặt vòng van $100 \%$, cắt tứ giác $36 \%$, khâu gấp nếp lá sau $50 \%$, chồng dây chằng nhân tạo $14 \%$. Tỉ lệ tử vong trong bệnh viện và 30 ngày sau mổ là $0 \%$. Không có trường hợp nào chảy máu phải mổ lại. Các biến chứng ghi nhận bao gồm 1 trường hợp đột quỵ $(4,5 \%), 1$ tràn dịch màng phổi $(4,5 \%)$ 1 tràn dịch màng tim cần dẫn lưu $(4,5 \%)$. Thời gian hồi sức trung bình $3 \pm 2$ ngày, thời gian thở máy $18.3 \pm 8.8$ giờ. Siêu âm tim sau phẫu thuật $(\mathrm{n}=22)$ đánh giá mức độ hở van: không hở hoặc rất nhẹ $(\mathrm{n}=10 ; 45,5 \%)$, hở nhẹ $(\mathrm{n}=10 ; 45,5 \%)$, hở vừa $(\mathrm{n}=2 ; 9 \%)$, hở nặng $(0 ; 0 \%)$. Có một trường hợp van hai lá hẹp nhẹ sau mổ, không cần can thiệp.

Tù khoá: Tạo hình van hai lá, it xâm lấn, nội soi hỗ trợ, phẫu thuật tim hơ

\section{SUMMARY}

This was a hospital-based cohort study including 22 prospective and retrospective patients who underwent minimally invasive mitral repair between 2015 and 2017. All enrolled patients had moderate to severe mitral regurgitation and transesophageal echocardiography done preoperatively. Operative techniques included peripheral cardiopulmonary bypass establishment, a $4 \mathrm{~cm}$ right mini-thoracotomy, a transthoracic aortic

\footnotetext{
* Trung tâm tim mach, Bệnh viện E

Ngườ chịu trách nhiệm khoa họ: GS.TS. Lê Ngoc Thành

Ngày nhận bài: 01/10/2017 - Ngày Cho Phép Đăng: 05/10/2017

Phản Biện Khoa học: GS.TS. Bùi Đức Phú PGS.TS. Đặng Ngọc Hùng
} 
cross-clamp, and antegrade cardioplegia. Mitral valve was exposed by using a selfmade pledgets and stitches hanging on the chest wall. Conventional left atrial retractor with supporting arm and rib retractor were not necessary. Almost all surgical manipulations were performed via thoracoscopic screen. The mitral valve exposure was good, 22 patients were operated on successfully. The mean age was $45.7 \pm 11.8$ years, $77.3 \%$ of the study population was male. The most predominant pathology was degenerative disease based on Carpentier classification, followed by functional mitral valve regurgitation Type II (77.3\%), rheumatic disease Type I (18.2\%). Cardiopulmonary bypass and aortic clamp times were $208.95 \pm 43.68$ and $143.09 \pm$ 39.95 minutes, respectively. Repair techniques included annuloplasty 100\%, leaflet resection $36 \%$, folding $50 \%$, neochordae implantation $14 \%$. Overall, inhospital and 30-day mortality were $0 \%$. There was no reoperation due to postoperative bleeding. The techniques were successfully applied in all patients without extending chest incision or conversion to median sternotomy. Major morbidities included 1 stroke (4.5\%), 1 pleural effusion $(4.5 \%)$ and 1 pericardial effusion (4.5\%) requiring intervention. The ICU length of stay was $3 \pm 2$ days, and average time to extubation was $18.3 \pm 8.8$ hours. At 30 days after operation, an echocardiography was performed to evaluate the degree of mitral regurgitation $(\mathrm{n}=22)$ which was none or trace $(\mathrm{n}=10,45.5 \%)$, mild $(\mathrm{n}=10,45.5 \%)$, moderate $(n=2,9 \%)$, or severe $(n=0,0 \%)$.

Keywords: mitral valve repair;totally endoscopic procedure; mitral valve's exposure

\section{I. ĐẶT VẤN ĐỀ}

Phẫu thuật sửa van hai lá trong bệnh cảnh hở van hai lá đơn thuần là một phương pháp mang lại nhiều ưu điểm cho người bệnh. Kể từ năm 1983, những cải tiến mới của Carpentier đã chỉ ra những lợi ích của sửa van hai lá có ưu thế hơn so với thay van hai lá nhân tạo [1]. Một số những ưu điểm bao gồm : tăng tỷ lệ sống, giảm nguy cơ viêm nội tâm mạc nhiễm khuẩn, giảm thiểu huyết khối gây tắc nghẽn và biến chứng liên quan đến việc dùng thuốc chống đông. Carpentier, Cosgrove, và David từng cho thấy: 92 đến 95 \% bệnh nhân không cần mổ lại khi sửa van hai lá qua đường mở ngực truyền thống trong vòng 10 năm sau mổ [2]. Chính những lợi ích này đã thuyết phục các phẫu thuật viên tim mạch lựa chọn phương pháp sửa van hơn là thay van hai lá.

Ngày nay, dưới sự phát triển của phẫu thuật nội soi, nhiều phương pháp tiếp cận van hai lá ít xâm lấn đã được nghiên cứu thực hiện trong đó phẫu thuật sửa van hai lá ít xâm lấn qua đường ngực phải đã chứng minh được những ưu điểm như tính an toàn, tỷ lệ tử vong sau mổ thấp, giảm sang chấn, ít đau, ít chảy máu, giảm thời gian thở máy, hồi sức và nằm viện, tính thẩm mỹ cũng như giảm thiểu tỷ lệ nhiễm trùng vết mổ và các biến chứng liên quan đến xương ức [3].

Tại trung tâm tim mạch bệnh viện E, 
chúng tôi đã tiến hành phẫu thuật sửa van hai lá nội soi từ đầu năm 2015 và thu lại được những kết quả nhất định. Nghiên cứu này phân tích kinh nghiệm của chúng tôi về phương pháp phẫu thuật này thông qua đánh giá kết quả lâm sàng của 22 bệnh nhân đã được sửa van nội soi trong vòng 20 tháng tại trung tâm tim mạch bệnh viện $\mathrm{E}$.

\section{II. ĐỐI TƯợNG VÀ PHƯƠNG PHÁP NGHIÊN CÚU}

\section{1. Đối tượng nghiên cứu}

\subsubsection{Tiêu chuẩn chọn bệnh nhân} nghiên cứu:Từ tháng 9 năm 2015 đến tháng 5 năm 2017, tại Trung tâm tim mạch Bệnh viện $\mathrm{E}$, chúng tôi tiến hành 22 ca phẫu thuật sửa van nội soi qua đường mở nhỏ ngực phải. Tất cả các bệnh nhân đều được chẩn đoán hở van hai lá đơn thuần từ mức độ vừa đến nhiều theo phân loại của Carpentier và chấp thuận phương án phẫu thuật/nghiên cứu này.

2.1.1. Tiêu chuẩn loại trừ: Tiêu chuẩn loại trừ bao gồm bệnh nhân có tổn thương vôi hoá van hai lá, chức năng tâm thu thất trái giảm (Phân suất tống máu $\mathrm{EF}<30 \%$ ), tăng áp lực động mạch phổi nặng $(>70 \mathrm{mmHg})$, động mạch vành có tổn thương cần phẫu thuật bắc cầu nối chủ vành, bệnh lý van động mạch chủ kèm theo, bệnh nhân có tiền sử phẫu thuật tim, chấn thương lồng ngực bên phải, những trường hợp đặc biệt như tổn thương van hai lá do viêm nội tâm mạc nhiễm khuẩn hoặc áp xe dưới van, hở van hai lá bẩm sinh cũng không được chọn lựa vào nghiên cứu của chúng tôi.

Ở những bệnh nhân trên 50 tuổi hoặc có yếu tố nguy cơ cao, chụp động mạch vành qua da để đánh giá tổn thương mạch vành là thường quy. Tất cả các bệnh nhân đều được siêu âm tim qua thành ngực trước mổ, sau mổ, và siêu âm tim qua thực quản trong mổ.

2.2. Phương pháp nghiên cứu: Tất cả bệnh nhân được phẫu thuật theo một quy trình thống nhất. Bệnh nhân gây mê, ống nội khí quản một nòng, tư thế nằm nghiêng $30^{\circ}$. Thiết lập tuần hoàn ngoài cơ thể ngoại vi: đặt ống động mạch vào động mạch đùi chung phải qua đoạn mạch nhân tạo Dacron số 8, trong trường hợp động mạch đùi nhỏ (không đủ áp lực tưới máu ngược dòng) đặt thêm ống động mạch thứ hai vào động mạch đùi chung trái (đặt trực tiếp với kĩ thuật Seldinger); Đặt ống tĩnh mạch thứ nhất vào tĩnh mạch đùi phải luồn lên tới tĩnh mạch chủ dưới (siêu âm thực quản kiểm tra); Đặt ống tĩnh mạch thứ hai vào tĩnh mạch chủ trên, theo đường tĩnh mạch cảnh trong phải qua da. Đặt trocart $6 \mathrm{~mm}$ khoang liên sườn IV đường nách giữa bên phải đặt ống kính nội soi. Mở ngực nhỏ trước bên phải $4 \mathrm{~cm}$ vị trí dưới nếp lằn vú ở nữ, khoang liên sườn $\mathrm{V}$ ở nam, mở vào khoang màng phổi vị trí khoang liên sườn IV. Bảo vệ cơ tim bằng cặp động mạch chủ qua thành ngực (Clamp Chitwood -khoang liên sườn II đường nách trước) truyền dung dịch liệt tim xuôi dòng qua gốc động mạch chủ (dung dịch Custodiol HTK). Sau khi tim ngừng đập, phẫu tích rãnh liên nhĩ mở nhĩ trái bộc lộ van hai lá: khâu treo nâng nhĩ trái bằng chỉ prolene 3/0 hoặc 4/0 kim 26 và miếng nhựa đệm; các sợi chỉ khâu treo được luồn, kéo qua thành ngực, cố định bằng panh, qua đó vách liên nhĩ, cơ thành bên nhĩ trái được kéo căng 
lên trên, ra trước bộc lộ van hai lá cho các thao tác sửa van.

\section{KẾT QUẢ}

Từ tháng 9 năm 2015 đến tháng 5 năm 2017, tại trung tâm tim mạch bệnh viện E, chúng tôi đã tiến hành $22 \mathrm{ca}$ phẫu thuật sửa van nội soi qua đường mở nhỏ ngực phải. Tất cả các bệnh nhân đều được chẩn đoán hở van hai lá từ mức độ vừa đến nhiều theo phân loại của Carpentier và chấp thuận phương án phẫu thuật này. Tiêu chuẩn loại trừ bao gồm những nhóm bệnh nhân có tổn thương vôi hoá van hai lá nhiều, tăng áp lực động mạch phổi nặng ( áp lực động mạch phổi $>70 \mathrm{mmHg}$ ), chức năng tâm thu thất trái kém ( Phân suất tống máu $\mathrm{EF}<20 \%$ ), và động mạch vành có tổn thương cần phẫu thuật bắc cầu nối chủ vành. Ngoài ra những trường hợp đặc biệt như tổn thương van hai lá do viêm nội tâm mạc nhiễm khuẩn hoặc áp xe dưới van, hở van hai lá bẩm sinh cũng không được chọn lựa vào nghiên cứu của chúng tôi. Ở những bệnh nhân trên 50 tuổi hoặc có yếu tố nguy cơ cao, chụp động mạch vành qua da để đánh giá tổn thương mạch vành là thường quy. Tất cả các bệnh nhân đều được siêu âm tim qua thành ngực trước mổ, sau mổ, và siêu âm tim qua thực quản trong mổ.

\section{1. Đặc điểm lâm sàng và cận lâm sàng}

Tuổi trung bình của những bệnh nhân phẫu thuật sửa van hai lá nội soi là $45,7 \pm$ 11,8 tuổi; $77,3 \%$ trong số nghiên cứu là nam. Thương tổn phổ biến nhất dựa trên phân loại Carpentier là hở hai lá do thoái hoá Type II (77,3\%), bệnh van hai lá do thấp I $(18,2 \%)$. Các đặc điểm lâm sàng như NYHA, bệnh lý kèm theo, và các đặc điểm cận lâm sàng, thăm dò chức năng được mô tả trong bảng 1 dưới đây.

\section{Bảng 3.1 : Đặc điểm bệnh nhân}

Đặc điểm

Tuổi ( giá trị trung bình \pm SD )

Tuổi ( khoảng dao động)

Tiền sử và bệnh lý kèm theo

Tăng huyết áp

Đái tháo đường

Hút thuốc lá

Rung nhĩ

Bệnh động mạch vành đã can thiệp

Suy thận

Bệnh tim trước đó (osler)

Phân loại NYHA

NYHA I
Giá trị

$45.7 \pm 11.8$

20-64

$4(18.2 \%)$

$1(4.5 \%)$

$6(27.2 \%)$

$2(9.1 \%)$

$1(4.5 \%)$

$1(4.5 \%)$

$1(4.5 \%)$ 
NYHA II

NYHA III-IV

Các chỉ số trên siêu âm tim

$\mathrm{LVEF}$, giá trị trung bình $\pm \mathrm{SD}(\%)$

Dd

Ds

Kích thước nhĩ trái

Áp lực động mạch phổi - giá trị trung bình $\pm \mathrm{SD}, \mathrm{mmHg}$

Áp lực động mạch phổi - khoảng dao động, mmHg

Tăng áp lực động mạch phổi

Hở hai lá nhiều

Hở ba lá vừa

XQ tim phổi - chỉ số tim ngực
$2(17.4 \%)$
$17(82.6 \%)$
$4(17.4 \%)$
$70.8 \pm 8.6$
$59.1 \pm 6.3 \mathrm{~mm}$
$34.6 \pm 5.1 \mathrm{~mm}$
$42.4 \pm 8.1$
$35.9 \pm 13.1$
21-66
$12(54.5 \%)$
$21(95.4 \%)$
$12(37.9 \%)$
$0.6 \pm 0.05$

\section{*NYHA : New York Heart Association}

\section{2. Đặc điểm trong mổ}

Kết hợp những ưu điểm của nội soi vào phẫu thuật tim hở, chúng tôi đã áp dụng những kĩ thuật tạo hình van hai lá như : cắt tam giác/tứ giác lá sau, khâu gấp nếp lá sau, chồng dây chẳng nhân tạo lá trước, đặt vòng van hai lá kín/ hở. Chúng tôi đang thử thách với những kĩ thuật khó hơn, có thể áp dụng nhiều hơn trong tương lai gần như chuyển vị trí dây chẳng lá trước, thu ngắn chiều dài cột cơ, sliding plasty, edge - to - edge ... Tî lệ ứng dụng các kĩ thuật được thể hiện trong bảng 2 dưới đây.

\section{Bảng 3.2 : Các kĩ thuật sửa van hai lá}

Đặc điểm

Đặt vòng van hai lá

Kích thước vòng van trung bình (khoảng dao động)

Cắt tam giác/tứ giác lá sau

Khâu gấp nếp lá sau

Tạo hình dây chằng nhân tạo lá trước
Giá tri

$22(100 \%)$

$29.8 \pm 1.3(28-32)$

$8(36 \%)$

$11(50 \%)$

$3(14 \%)$

Bảng 3 thể hiện những đặc điểm trong, sau mổ bao gồm : thời gian cặp động mạch chủ, thời gian chạy máy tuần hoàn ngoài cơ thể (THNCT), số lượng đơn vị máu truyền trong thời gian mổ và theo dõi bệnh nhân tại khoa hồi sức sau mổ. Trong nghiên cứu của chúng tôi ko có bệnh nhân nào phải chuyển mổ qua đường mở xương ức hay nặng nề hơn là tử vong trong mổ. 


\section{Bảng 3.3 : Các đặc điểm trong, sau mổ}

Đặc điểm

Thời gian chạy máy THNCT, phút

Thời gian cặp ĐMC, phút

Truyền máu

Hồng cầu trong mổ, đơn vị (1đơn vị = 250ml)

Hồng câu sau mổ

Đặc điểm tim đập ngay sau thả cặp ĐMC

Nhịp xoang

Rung thất cần shock điện

Nhịp chậm

Thời gian $\mathrm{ICU}$, giờ

Thời gian rút ống NKQ, giờ

Thời gian nằm viện, ngày
Giá trị

$212 \pm 40.2$

$145.1 \pm 40.2$

$3 \pm 1.6$

$0.64 \pm 1.84$

$4(18.2 \%)$

$1(4.5 \%)$

$17(77.3 \%)$

$76.8 \pm 52.8$

$18.1 \pm 8.6$

$14.6 \pm 6.8$

\subsection{Kết quả sớm sau mổ}

Đánh giá sớm sau mổ cho thấy không có bệnh nhân nào tử vong sớm sau mổ trong nghiên cứu của chúng tôi và không có trường hợp nào cần mổ lại. Tuy nhiên chúng tôi cũng ghi nhận những biến chứng như: 2 trường hợp có máu cục màng phổi, 2 trường hợp nhiễm trùng nhẹ vết mổ cần làm sạch và dùng kháng sinh điều trị, 3 trường hợp tràn dịch màng phổi cần đặt dẫn lưu, 1 trường hợp viêm phổi cần điều trị kháng sinh và không có nhiễm khuẩn huyết. Trong đó có 1 trường hợp biến chứng nặng nề nhất là tai biến mạch máu não với di chứng liệt không hoàn toàn tay trái và thất ngôn.

3.4. Đánh giá kết quả thay đổi trên siêu âm tim và theo dõi bệnh nhân sau mổ

Trình bày trong bảng 4 dưới đây là kết quả siêu âm tim trước khi ra viện của 22 bệnh nhân. Trong đó có 2 bệnh nhân hở hai lá vừa với các triệu chứng lâm sàng ổn định được tiếp tục theo dõi, các bệnh nhân còn lại mức độ hở rất nhẹ hoặc hở nhẹ van hai lá. Bên cạnh đó sự cải thiện đáng kể các chỉ số trên siêu âm cho thấy những kết quả khả quan bước đầu khi theo dõi bệnh nhân phẫu thuật sửa van hai lá nội soi.

\section{Bảng 3.4 : So sánh siêu âm tim trước mổ và sau mổ}

\begin{tabular}{|c|c|c|c|}
\hline Các chỉ số SÂ tim & $\begin{array}{l}\text { SA trước mồ } \\
T B \pm \text { dộ lệch }\end{array}$ & $\begin{array}{l}\text { SÂ lúc ra viện } \\
T B \pm \text { độ lệch }\end{array}$ & $p$ \\
\hline$N T(m m)$ & $42.4 \pm 8.1$ & $36.3 \pm 5.8$ & 0.0064 \\
\hline$D d(m m)$ & $59.1 \pm 6.3$ & $48.6 \pm 5.1$ & $<0.0001$ \\
\hline$D s(m m)$ & $34.6 \pm 5.1$ & $31.7 \pm 4.3$ & 0.0478 \\
\hline
\end{tabular}



$E F(\%)$
ALĐMPTT
$70.8 \pm 8.6$
$61.1 \pm 6.1$
Mức độ hở van hai lá
$35.9 \pm 13.1$
$23.8 \pm 4.1$
Không hở hoặc rất nhẹ
0
$10(45.5 \%)$
Nhẹ
0
$10(45.4 \%)$
Vừa
1 ( $4.5 \%)$
$2(9.1 \%)$
Nhiều
$21(95.47 \%)$
0

0.0001

0.0002

\section{BÀN LUẬN}

Phẫu thuật sửa van hai lá ít xâm lấn có nội soi hỗ trợ đã được tiến hành tại nhiều trung tâm phẫu thuật tim trên thế giới với những kết quả xuất sắc. Bắt đầu từ ca sửa van đầu tiên năm 1996 của Carpentier và CS, phẫu thuật van hai lá ít xâm lấn đã có những bước tiến mạnh mẽ, đặc biệt với sự hỗ trợ của robot, nhiều nghiên cứu đã được công bố với đường mở ngực phải $4 \mathrm{~cm}$, hoặc nội soi hoàn toàn với đường mở ngực chỉ $1.5 \mathrm{~cm}$ [4]. Tại Trung tâm tim mạch bệnh viện $\mathrm{E}$ phẫu thuật van hai lá ít xâm lấn nội soi hỗ trợ đã được triển khai từ 2013, cho tới nay thay van hai lá với phương pháp này đã trở thành thường quy. Đối với sửa van hai lá, chúng tôi thực hiện từ nửa đầu 2015, khi các thao tác với phẫu trường mới bắt đầu trở nên thuần thục. Trong giai đoạn này, chúng tôi chủ động lựa chọn bệnh nhân với những tổn thương đơn giản như đơn thuần lá sau - với các kĩ thuật tạo hình van hai lá không quá phức tạp

Theo kinh nghiệm của chúng tôi, một trong những khó khăn nhất của phẫu thuật là sự bộc lộ hoàn chỉnh van hai lá trong toàn bộ cuộc mổ, điều đó dẫn tới những thử thách nhất định trong quá trình sửa van bao gồm đặt vòng van hai lá (nhất là vòng van kín), sửa chữa các lá van, kiểm tra hoạt động của van. Trong thực hành lâm sàng có nhiều bộ dụng cụ khác nhau được sử dụng để kéo nâng tâm nhĩ bộc lộ van. Cấu hình kỹ thuật hầu hết sử dụng một cánh tay đòn xuyên qua thành ngực, sau đó gắn với một má kim loại mỏng áp sát vào vách liên nhĩ kéo vách liên nhĩ ra trước, cánh tay đòn được cố định vào khung banh ngực [5]. Các bộ dụng cụ này thường có giá thành cao nhưng vẫn tồn tại nhược điểm thường phải tạo một lỗ 4-5mm qua thành ngực (nguy cơ chảy máu sau mổ). Trong nhiều tình huống lâm sàng chọn vị trí tối ưu để đặt dụng cụ này gặp khó khăn, vướng vào phẫu trường. Phương pháp của chúng tôi sử dụng các mũi chỉ khâu kéo nâng thành tâm nhĩ không phải mở thêm lỗ qua thành ngực do đó hạn chế nguy cơ chảy máu sau mổ, dễ dàng chọn và thay đổi vị trí cho phù hợp mà không gây sang chấn, phương tiện đơn giản (không cần bộ dụng cụ phức tạp, giá thành cao), thao tác dễ dàng và tiết kiệm thời gian phẫu thuật, đặc biệt đạt mục đích bộc lộ bộ máy van hai lá tốt nhất, phẫu trường mổ rõ ràng không bị vướng bởi dụng cụ. Hơn nữa với những trường hợp nhĩ trái nhỏ, trường mổ sâu, có thể đặt thêm các mũi chỉ treo ở các "góc chết", qua đó việc bộc lộ van hai lá được thực hiện một cách linh hoạt. Kỹ thuật đã được áp dụng thành công cho toàn bộ 22 bệnh nhân nghiên cứu của chúng tôi. Không có trường hợp nào phải chuyển mở xương ức 
hay mở rộng đường mở ngực. Phương pháp an toàn, kết quả sớm phẫu thuật không có bệnh nhân nào chảy máu phải mổ lại. Theo dõi 30 ngày sau phẫu thuật tỉ lệ tử vong là $0 \%$

Một trường hợp đột quỵ được ghi nhận trong 22 bệnh nhân nghiên cứu, để lại di chứng yếu tay trái cơ lực $2 / 5$ và thất ngôn broca. Tất cả các bệnh nhân chúng tôi dự kiến phẫu thuật sửa van hai lá nội soi đều được siêu âm mạch chi dưới, động mạch chậu, động mạch chủ bụng để đánh giá tình trạng xơ vữa, vôi hoá mạch máu có thể trở thành nguy cơ với quá trình tưới máu ngược dòng. Với các bệnh nhân có yếu tố nguy cơ cao về bệnh mạch máu ví dụ đái tháo đường, tăng huyết áp, tiền sử hút thuốc lá nặng, chụp cắt lớp vi tính động mạch chủ có thể được cân nhắc. Mặc dù không thể loại trừ hết các yếu tố nguy cơ với quá trình tưới máu ngược dòng, song chúng tôi tin rằng với các xét nghiệm cận lâm sàng trước mổ có thể giảm thiểu tối đa các biến chứng liên quan đến thần kinh. Trong suốt quá trình phẫu thuật, chúng tôi bơm $\mathrm{CO} 2$ với lưu lượng $0,51 /$ phút để giảm thiểu các bọt khí xuất hiện trong nhĩ trái và thất trái, tuy nhiên tỷ lệ đột quỵ có thể xảy ra do quá trình đuổi khí khó khăn bởi phẫu trường của phẫu thuật nội soi.

Trên hết, chúng tôi cảm thấy hài hòng với những kết quả lâm sàng mà phẫu thuật sửa van hai lá nội soi đạt được. Chúng tôi tin rằng cùng với sự phát triển của khoa học kĩ thuật, đặc biệt ứng dụng của các hệ thống robot đã triển khai ở các nước phát triển, chất lượng của phẫu thuật nội soi sửa van hai lá sẽ không ngừng cải thiện, ngày càng khả thi. Phẫu thuật tim hở nội soi toàn bộ sửa van hai lá sẽ trở thành một $\mathrm{xu}$ hướng tại các trung tâm phẫu thuật tim mạch Việt Nam.

\section{KẾT LUẬN}

Phẫu thuật sửa van hai lá ít xâm lấn tại trung tâm tim mạch bệnh viện $\mathrm{E}$, với những cải tiến kỹ thuật trong bộc lộ van hai lá: dễ thực hiện, đạt được mục đích bộc lộ van hai lá với những phương tiện đơn giản. Kết quả ngay sau phẫu thuật và theo dõi sau một tháng hiệu quả, an toàn.

\section{TÀI LIỆU THAM KHẢO}

1. A.Carpentier, David H.Adams et al (2010), $C$ A $A \begin{array}{lllllllllll} & P & E & N & T & I & E & R\end{array}$, SReconstructiveValve SurgeryFrom Valve Analysis to Valve Reconstruction. Saunders Elsevier; $3-5$.

2. Aubrey C. Galloway, et al (2009), A Decade of Minimally Invasive Mitral Repair:Long-Term Outcomes.Ann Thorac Surg 2009;88:1180-4

3. Tayfun Aybek, MD,Selami Dogan, et al (2006), Two Hundred Forty Minimally Invasive Mitral Operations Through Right Minithoracotomy. Ann Thorac Surg, (81) $1618-24$.

4. L. Wiley Nifong, et al (2012), 540 Consecutive Robotic Mitral Valve Repairs IncludingConcomitant Atrial Fibrillation Cryoablation.Ann Thorac Surg 2012;94:38-43

5. Eugene A. Grossi, MD, Aubrey C. Galloway (2002). Minimally Invasive Mitral Valve Surgery: A 6-Year Experience With 714 Patients. Ann Thorac Surg

Paul Modi, Ansar Hassan (2008), Minima lly invasive mitral valve surger $y$ : a syste matic revie and meta-ana lysis. European Journal of Cardio-thoracic Surgery; (34) 943-952. 